\title{
Palavras, ideias e tensões: as relações conflituosas entre o sínodo rio-grandense e a secretaria de educação do Rio Grande do Sul (1938 - 1943)
}

\author{
Words, ideas and tensions: the conflict relations between the rio grandese synod and the secretary of \\ education of Rio Grande do Sul (1938 - 1943)
}

\section{Rodrigo Luis dos Santos}

Instituto Superior de Educação Ivoti - ISEI - Ivoti - Rio Grande do Sul - Brasil

\begin{abstract}
Resumo: O objetivo deste trabalho é apresentar aspectos da relação entre o Sínodo Rio-grandense, órgão responsável por dirigir os evangélico-luteranos no Rio Grande do Sul, presidido nesse período pelo pastor Hermann Gotlieb Dohms, e a Secretaria Estadual de Educação, chefiada por José Pereira Coelho de Souza. Esta relação, marcadamente conflituosa e tensa, tem seu período de maior atrito entre 1938 e 1943, com a implantação do Estado Novo e da Campanha de Nacionalização (a partir de 1938) e com o rompimento das relações diplomáticas do Brasil com a Alemanha (1942). Buscaremos aqui, apresentar alguns pontos dessa relação e argumentos utilizados pelos envolvidos.
\end{abstract}

Palavras-chave: Conflito. Religião. Nacionalização.

\begin{abstract}
The objective of this work is to present aspects of the relationship between the Rio-grandense Synod, the organ responsible for directing Evangelical Lutherans in Rio Grande do Sul, presided over by Pastor Hermann Gotlieb Dohms, and the State Secretary of Education, headed by José Pereira Coelho de Souza. This relationship, markedly conflictual and tense, had its period of greatest friction between 1938 and 1943, with the establishment of the Estado Novo and the Nationalization Campaign (from 1938) and with the disruption of diplomatic relations of the Brazil with Germany (1942). We will seek here, to present some points of this relation and arguments used by those involved.
\end{abstract}

Keywords: Conflicts. Religion. Nationalization. 


\section{Uma breve perspectiva}

A historiografia acerca do período do Estado Novo no Brasil, entre 1937 e 1945, tem lançado luzes sobre as relações entre o governo brasileiro e as chamadas minorias étnicas, com destaque para alemães, italianos, poloneses, judeus, entre outras. Os principais trabalhos focam sua análise no Sul e Sudeste do Brasil. Um fator importante que tem contribuído significativamente para novos panoramas de análise desse período, assim como para a exposição de informações até então não consideradas úteis, é o emprego de metodologias historiográficas como a Micro-história, que permitem analisar detalhes e nuances nem sempre vistos como proveitosos. Deste modo, uma compreensão mais crítica permite avaliar os acontecimentos sem se deixar levar pelas generalizações. Permite perceber rupturas, articulações, ações individuais, formação de redes, tentativas de rompimento com os ditames sociais, entre outros aspectos variados, que proporcionam uma visão mais complexa das estruturas sociais e políticas.

Esse quadro historiográfico tem oportunizado uma nova dimensão de pesquisa em muitas temáticas consideradas, inclusive, já esgotadas. Com as questões referentes ao Estado Novo, as políticas nacionalizadoras, as instituições e agentes históricos envolvidos, esse novo dimensionamento também tem contribuído para produtivas abordagens, novos questionamentos e apreciações para argumentos e conclusões tidas como definitivas. Nesse breve ensaio, iremos analisar, mesmo de forma ainda não tão aprofundada como a temática merece, como se desenvolveram as relações entre o Sínodo Riograndense e a Secretaria de Educação e Saúde Pública do Rio Grande do Sul ${ }^{1}$, sobretudo entre os anos de 1938 e 1943, quando não apenas os argumentos, mas as ações se mostram mais

\footnotetext{
${ }^{1}$ Posteriormente, com o Decreto-Lei estadual número 31, de 06 de setembro de 1940, o Departamento de Saúde seria desvinculado da Secretaria de Educação, formando um departamento autônomo. A Secretaria de Educação e Saúde Pública passaria a receber a denominação de Secretaria da Educação do Estado do Rio Grande do Sul.
}

drásticas. Também buscamos apresentar elementos que colaboram com nossa percepção de que esta temática ainda pode oferecer profícuas interpretações, renovando a historiografia sobre este período histórico republicano.

Durante muito tempo, mesmo no meio acadêmico, vigorou a ideia de que as ações políticas de nacionalização, determinadas pelos governantes tanto em nível nacional, como estadual e nos municípios, foram impostas de forma tão incisiva que, em poucos casos, sofriam tentativas de impedimento ou de amenização. Contudo, novas pesquisas apontam para buscas de reação diante das ações estadonovistas. A forma que estas estratégias e ações foram articuladas, o insucesso ou o êxito das mesmas, os pormenores, os ajustes, as estratégias, esses elementos inculcados nos meandros das grandes ações é que permitem vislumbrarmos esse período histórico brasileiro e sul-rio-grandense com novos olhares. Nesse breve escrito, iremos lançar um olhar sobre a dimensão relacional entre o órgão representativo dos evangélico-luteranos ${ }^{2}$ e o órgão governamental, juntamente com a polícia estadual, mais empenhado em efetivar as políticas de nacionalização vigentes no período. Como fontes para essa interpretação, iremos nos ater em correspondências $^{3}$ trocadas entre José Pereira Coelho de Souza, secretário estadual de Educação entre 1937 e 1945, e o pastor Hermann Gotlieb Dohms, presidente do Sínodo Rio-grandense entre 1935 e 1956. O principal conteúdo destas correspondências aborda temas pertinentes ao

\footnotetext{
2 O termo evangélico-luterano foi utilizado pela historiadora Isabel Cristina Arendt em sua Tese de Doutoramento (2005), para se referir aos membros do Sínodo Rio-grandense. Faz-se essa distinção, pois existem duas correntes luteranas no período, e que dariam origem a suas Igrejas hoje existentes: o Sínodo Rio-Grandense, com ligação mais direta com a Igreja Evangélico-Luterana Alemã, daria origem à Igreja Evangélica de Confissão Luterana no Brasil (IECLB), a partir de 1949, ante a fusão com sínodos de outros estados, oficializada em 1968; e o Sínodo de Missouri, originado de imigrantes alemães dos Estados Unidos, que chegariam ao Rio Grande do Sul em 1900, dando origem à Igreja Evangélica Luterana do Brasil (IELB), independente do Sínodo de Missouri desde 1980.

${ }^{3}$ Arquivo Histórico da IECLB (Faculdades EST - São Leopoldo) - Fundo Sínodo Rio-grandense - Caixa SR 17 - Pasta SR 17/6 - Documentos 009 e 013.
} 
processo de nacionalização das escolas privadas, mas também apontam para percepções políticas mais amplas, como poderemos ver mais adiante.

\section{0 que os documentos podem nos mostrar}

Em documento datado de 13 de setembro de 1941, Coelho de Souza elenca ao presidente do Sínodo Rio-grandense, pastor Hermann Dohms, razões sobre as quais sustenta sua postura mais incisiva sobre os educandários pertencentes ou vinculados ao Sínodo. Esse documento enviando ao pastor Dohms é, por sua vez, resposta a um ofício encaminhado pelo mesmo à secretaria de Educação, cobrando das autoridades governamentais, uma postura de tratamento mais igualitária e a autorização para o uso da língua alemã nos cultos e ofícios religiosos. Além destas e de outras solicitações, o pastor Hermann Dohms acusa Coelho de Souza de beneficiar as entidades educacionais católicas, sendo que muitas também descumprem, segundo Dohms, certas regras determinadas pela nacionalização do ensino.

Em resposta, o secretário de Educação argumenta que também buscou se aproximar e firmar acordos com outras denominações religiosas, como o Sínodo Evangélico Luterano do Brasil (Sínodo de Missouri) e as Igrejas Metodista, Episcopal e Adventista. Também afirma que as atitudes hostis e as tentativas de não se adequar às leis de nacionalização impediram um acordo com o Sínodo Rio-grandense. Muitos educandários tentam, segundo argumenta, burlar as normas, estabelecendo um clima de animosidade. Fiscais de ensino, enviados pela Secretaria de Educação, são hostilizados, além de não haver, segundo Coelho de Souza, uma real vontade de formar cidadãos brasileiros dentro de algumas escolas sinodais.

Embora não detalhe mais enfaticamente neste documento, mas diante das pesquisas realizadas ${ }^{4} \mathrm{e}$

\footnotetext{
4 Para maiores informações, queira ver: SANTOS, Rodrigo Luis. As escolas confessionais como instrumento de ação política de grupos de alemães e descendentes no contexto do Estado Novo (o caso das escolas Santa Catarina e Fundação Evangélica de Novo
}

documentos consultados, um dos educandários que assinalam para esta dificuldade de adequação é a Fundação Evangélica, situada no município de Novo Hamburgo. Uma série de documentos existentes no Arquivo Histórico da IECLB ${ }^{5}$ apontam que, desde 1938, ocorrem ameaças de estatização ou fechamento da instituição por parte das autoridades estaduais, mas que tanto as lideranças dirigentes da escola quanto as autoridades sinodais tentam evitar estas ações, inclusive contando com a mediação de lideranças políticas, como o prefeito de Novo Hamburgo, Odon Cavalcanti, amigo de Getúlio Vargas, ou empresários, como Benno Mentz e A. J. Renner.

Para embasar sua argumentação, Coelho de Souza explica que as principais razões para sua conduta podem ser encontradas nas páginas 10 e 95 do relatório O Nazismo no Rio Grande do $\mathrm{Sul}^{6}$, de autoria do chefe de Polícia Aurélio da Silva Py. No relatório, posteriormente publicado na forma de livro, nas páginas citadas pelo secretário de Educação, Aurélio Py aborda, entre outros pontos, um plano de expansão alemã no sul da América do Sul, abarcando o Rio Grande do sul, além de tratar de espionagem nazista com apoio de lideranças alemãs no estado, como Otto Ernst Meyer, um dos fundadores da Viação Aérea Rio-Grandense (VARIG).

Mas um ponto importante que o chefe de Polícia aborda é a utilização da Igreja Evangélica Alemã como um dos principais instrumentos do Partido Nazista. E a Igreja Evangélica da Alemanha, ao ter relações com instituições em outros países, como o Sínodo Rio-grandense, no Brasil, utilizaria a religião como meio de arregimentação e propagação nazista pelo mundo. Essa constatação por parte das autoridades seria um elemento norteador das ações empreendidas a partir de 1940, como prisão de pastores evangélico-luteranos e uma ação policial

Hamburgo - RS). Trabalho de Conclusão de Curso (Graduação em História) - Universidade do Vale do Rio dos Sinos - UNISINOS, 2013.

${ }^{5}$ Arquivo Histórico da IECLB (Faculdades EST - São Leopoldo) - Fundo Sínodo Rio-grandense (SR) - Caixa SR 17 - Pastas SR 17/1, 17/2, 17/3, 17/4, 17/5, 17/6, $17 / 7$ e $17 / 8$.

${ }^{6}$ PY, Aurélio da Silva. O Nazismo no Rio Grande do Sul (Documento secreto n.59). Porto Alegre, 1940, v.1. 
mais repressora. Entre os presos, no ano de 1941, podemos citar o pastor Wilhelm Pommer, pároco da Comunidade Evangélica de Hamburgo Velho, em Novo Hamburgo, e até então presidente do Curatório, espécie de entidade mantenedora da Fundação Evangélica. O pastor Pommer, assim como outros presos, é enviado para a Colônia Penal Agrícola General Daltro Filho, na cidade de Charqueadas. Neste período, entre 1941 e 1943, a documentação ${ }^{7}$ lista o nome de 26 pastores alemães que foram detidos na Colônia Daltro Filho, sendo muitos, conforme fontes encontradas, vítimas de maus tratos graves e de enfermidades decorrentes do encarceramento ${ }^{8}$.

Coelho de Souza, além de reafirmar no documento expedido que não permitirá que se continue com os ofícios religiosos em língua alemã, tendo em vista que as demais igrejas o fazem em língua nacional, afirma que o idioma alemão, ao contrário do latim utilizado pelos católicos, é uma língua que está sendo usada como instrumento imperialista por parte do nazismo. Por fim, acusa o Sínodo Rio-grandense de permitir o ofício de aulas de geografia, história e linguagem em seus templos.

Evidentemente, a escrita de um documento está imbuída de uma intencionalidade, de uma finalidade a qual está servindo. Ao nos lançarmos na análise da documentação e estabelecermos considerações sobre as informações, precisamos ter em mente os agentes que elaboraram esta documentação e o contexto em que foram redigidas. Mas esta breve apreciação destes documentos aqui selecionados nos ajudam a perceber alguns pontos importantes. Aqui iremos considerar três pontos que julgamos pertinentes.

Primeiramente, podemos tecer um panorama sobre a conjuntura e o clima social e político que se instala no Brasil a partir de 1941. Nas considerações de Coelho de Souza, ao apontar para possíveis

\footnotetext{
${ }^{7}$ Arquivo Histórico do Rio Grande do Sul - Fundo Polícia - Maço 151 - Correspondência expedida pela Repartição Central de Polícia, 1941/1942; Maço 153 Documentos da Delegacia de Ordem Pública e Social (DOPS), 1942.

Arquivo Histórico da IECLB - Fundo Sínodo Riograndense (SR) - Caixa SR 18 - Pastas SR 18/1.
}

intenções imperialistas alemãs e a necessidade de impedir que este processo se deflagre, é perceptível que existe um afastamento considerável nas relações que o Brasil possuía com a Alemanha e um alinhamento com o pensamento advindo do governo dos Estados Unidos, que muito colaborou para a disseminação da ideia do imperialismo alemão na América. Aqui não refutamos que esta possibilidade tenha sido cogitada e até planejada pelo governo da Alemanha, mas nos chama a atenção que o discurso das autoridades nacionais passa por uma mudança, sendo que até pouco tempo antes, a ideia de ação do III Reich não era vista como algo tão perigoso. Com isso, se percebe que as relações diplomáticas entre o Brasil e os países envolvidos na guerra são acentuadamente maleáveis. Neste sentido, Andrea Rahmaier argumenta que

as relações entre Brasil e Alemanha, no
período de 1930 a 1942 [...] foram guiadas
pelas circunstâncias. Confirma-se a
presença de partidários nazistas, mas não
constitui ameaça ao regime governamental
vigente no Brasil. As relações
diplomáticas, políticas e militares foram
guiadas pelas circunstâncias do contexto
histórico vivenciado, isto é, as ações da
política exterior foram sendo estruturadas
aos poucos, pois não estavam
predeterminadas. Por isso, uma análise
desse período exige detalhamentos. Com
o início da guerra na Europa, as ações
diplomáticas foram subordinadas aos
interesses militares, mas não há indícios
de que o III Reich pensasse em conquista
territorial na América (RAHMEIER, 2013,
p. 177).

O segundo aspecto que merece consideração são as relações e acordos que foram estabelecidos entre o governo estadual e diferentes instituições religiosas. Cabe destacar que este tema ainda carece de pesquisas mais profundas e de alcance qualitativo mais amplo. Neste caso, o acordo entre a Secretaria de Educação, por meio de Coelho de Souza, e a Igreja Católica, através do arcebispo D. João Becker, é o mais estruturado. A citação da existência deste acordo, firmado em 1940, suscita análises acerca dos critérios estabelecidos, dos fatores antecedentes e das ações decorrentes do acordado. Pesquisas apontam para a postura política do arcebispo de 
Porto Alegre, que ao longo de seus 34 anos de episcopado no Rio Grande do Sul (1912 - 1946), soube moldar suas posturas e ações conforme as conveniências políticas externas.

D. João Becker esteve, aparentemente, mais preocupado, dentro da conjuntura política, na manutenção de sua influência do que com os próprios rumos pastorais da Igreja Católica, embora agisse em nome desta e fizesse uso da estrutura institucional. Chamamos a atenção para uma questão importante, que diz respeito aos efeitos da Campanha de Nacionalização em instituições católicas. Em algumas escolas católicas, as ações de nacionalização também foram incisivas, inclusive com o fechamento de algumas. A maioria destas ações ocorreram antes de 1940, quando se firmou o acordo entre Igreja Católica e governo estadual. Destacamos aqui o episódio ocorrido em 1939, na cidade de Novo Hamburgo, onde a Escola Normal Católica, responsável pela formação de professores, foi fechada após uma visita do secretário Coelho de Souza. Este educandário era dirigido por padres jesuítas, sendo mantido pela Sociedade União Popular, a Volksverein, existente desde $1912^{9}$.

Em uma festividade em comemoração ao Dia do Colono, ocorrido em julho do referido ano, é convidado a participar das festividades o secretário de Educação Coelho de Souza. O convite parte de Leopoldo Petry, presidente da Sociedade União Popular. Era diretor da Escola normal o padre jesuíta Miguel Meier, S.J. Durante a cerimônia, um dos alunos teria proferido um discurso, que teria sido recebido por Coelho de Souza como demonstração de uma atitude contrária ao processo de nacionalização que vinha sendo implantado. Poucos dias depois, seria o momento do secretário de Educação proferir palavras de indignação ao ocorrido

\footnotetext{
9 Atual Associação Theodor Amstad, cuja sede está localizada no município de Nova Petrópolis. A Volksverein surgiu a partir de um Congresso Católico, o Katholikentage, realizado no ano de 1912, em Venâncio Aires. Teve como principal articulador o Padre Theodor Amstad, S.J., que também foi um dos responsáveis pela criação, em 1902, de um sistema de cooperativa de crédito, que hoje formam o Sistema de Crédito Cooperativo (SICREDI).
}

na Escola Normal, através dos jornais Correio do Povo e Diário de Notícias.

É interessante destacar que um ano antes, a impressão que teve da mesma foi diferente, conforme publicou no Correio do Povo:

\begin{abstract}
Dirigi-me, depois, a Escola Normal Catholica e situada no mesmo districto, a qual se achava em pleno fuccionamento. Ah! já se nota um grande passo no sentido da nacionalização, si bem que senti a falta de um professor que imprima mais aula brasileira aos alumnos. Não há duvida, porém, que todos falam e lêm correctamente o portuguez, supportando perguntas sobre historia e geographia do Brasil e conhecem bem o hymno brasileiro. Um detalhe da visita mostra o avanço já feito no sentido da nacionalização dos futuros professores catholicos. Os alumnos do curso normal, postos em fórma, cantaram perfeitamente a letra do hymno pátrio e, no curso de applicação, que funcciona annexo, todas as creanças, que não ultrapassam os 10 annos, já conheciam, tambem, perfeitamente o nosso canto nacional (Correio do Povo, Ano XLIV, 06/05/1938, $\mathrm{n}^{\circ} 105$, p. 14) ${ }^{10}$
\end{abstract}

A repercussão da segunda visita do secretário de Educação se mostra tempestuosa. Dom João Becker declara que apoiará todas as ações nacionalizadoras promovidas pelo governo, determinando que o clero e as ordens religiosas também tenham essa postura. $O$ arcebispo também não se esforça em tentar manter a Escola Normal em funcionamento, apoiando a decisão do governo estadual em determinar o fechamento do educandário. Mesmo com os esforços das lideranças católicas locais, como Leopoldo Petry, a decisão governamental acaba sendo cumprida. Episódios como o descrito ajudam a entender a postura e as ações tomadas pelo arcebispo de Porto Alegre nos anos seguintes, até o fim do Estado Novo, em 1945. Concomitantemente, neste período também ocorrera a prisão de algumas lideranças católicas, acusadas de flertarem com ideias nazistas, como é o caso do médico Wolfram Metzler, expressiva liderança integralista no estado, exercendo a chefia da agremiação em Novo Hamburgo até 1938 e um dos

${ }^{10}$ Optamos por manter nesta citação a grafia utilizada na época. 
proprietários da Typographia do Centro, em Porto Alegre, responsável pela publicação do jornal $A$ Nação. Fato interessante é que um dos irmãos de Wolfram, Franz Metzler, é apontado pelo chefe de Polícia Aurélio da Silva Py em seu livro como um dos principais apoiadores das ações do Estado Novo no combate ao nazismo no território sul-rio-grandense ${ }^{11}$.

E o terceiro ponto que destacamos está vinculado com a postura das autoridades do Sínodo Rio-grandense, no que se refere a sua postura de contrariedade diante de certas determinações governamentais. As acusações feitas pelo pastor Hermann Dohms, apontando a prática de favorecimento da Secretaria de Educação para com a Igreja Católica, mostra entre outras coisas, os atritos existentes ainda entre católicos e evangélicoluteranos, além de exemplificar uma mudança de atitude por parte do Sínodo Rio-grandense. Se até então, a postura se mostrava conciliadora, visando amenizar as relações e contornar dificuldades, a partir de 1942 se tornam claramente voltadas para a defesa das práticas religiosas e sociais desta parcela da população, atendida pela estrutura sinodal. A ação de Hermann Dohms mostra que, diante do panorama político e da conjuntura de crise, circunscrito pelas mudanças trazidas pela guerra, a forma de se defender passa a ser o ataque, o apontamento de questões que, segundo o Sínodo Rio-grandense, não condiziam com os discursos de justiça e igualdade propagados pelo governo. Reivindicações e queixas, constantes nas comunidades e instituições vinculadas ao Sínodo Rio-grandense, passam a ser explanadas na pauta de ações das altas autoridades sinodais. Essa mudança de postura ajuda a contrapor a argumentação, até hoje existente, de existir apenas passividade e falta de condições de reação por parte dos imigrantes e descendentes de alemães evangélico-luteranos, o grupo étnico mais perseguido pelo Estado Novo no sul do Brasil.

\section{Algumas conclusões}

11 PY, Aurélio da Silva. A 5 coluna no Brasil: A conspiração nazi no Rio Grande do Sul. 1. ed. Porto Alegre: Globo, 1942.
Ao vislumbrarmos os conflitos latentes entre 0 Sínodo Rio-grandense e a Secretaria de Educação do Rio Grande do Sul, podemos ter, mesmo que minimamente, uma perspectiva das estratégias adotadas por ambos diante da conjuntura do momento, tanto no tocante da política nacionalista brasileira, como no clima global de guerra, com a necessidade de se assumir o apoio a um dos lados envolvidos. Essa conjuntura mais ampla circunda uma realidade também complexa, que se desenvolve em nível local, marcada por uma constante tensão entre os grupos e agentes históricos envolvidos. E reside na análise dessas tensões, observando criticamente os detalhes, as entrelinhas, a oportunidade de se analisar a construção histórica e social de forma mais dinâmica e coerente.

Quando observarmos trocas de acusações entre Coelho de Souza e pastor Hermann Dohms, percebemos uma inserção política bastante forte por parte das lideranças evangélico-luteranas de origem alemã. Mais que isso, colabora para uma percepção de que, ao contrário dos discursos que as próprias autoridades políticas apregoavam, de um "isolamento" étnico, cultural e social dos imigrantes e descendentes de alemães, estes estavam inseridos, de uma forma ou outra, na sociedade brasileira, em menor ou maior grau. Evidentemente, pessoas residentes nos núcleos urbanos das áreas de imigração possuíam um nível de informação maior que os residentes nas áreas rurais. Mas estes também, mesmo em menor grau, buscavam também participar de certos aspectos da sociedade. Assim, tanto para o período do Estado Novo como para o presente, a tese do isolamento já não é mais viável.

Por fim, outro discurso que ainda se faz presente, que defende apenas a vitimização dos imigrantes e descendentes durante o Estado Novo e a Segunda Guerra Mundial, encontra nas novas pesquisas sobre o tema argumentos de oposição. As informações proporcionadas na documentação decorrente deste período evidenciam tentativas de reação, tanto em núcleos urbanos como nas áreas mais rurais do interior do estado. Não refutamos aqui, o que seria um erro grave, a existência de violências 
e ações repressivas truculentas por parte das autoridades governamentais. Prisões, proibições de uso de língua estrangeira, imposições de regras educacionais, apreensão e destruição de livros e objetos pessoais, acusações sem fundamentação, todos estes fatores estão inseridos na composição do cenário estadonovista, entre 1937 e 1945. Mas aqui defendemos a ideia de tentativas de reação diante destas medidas. $\mathrm{E}$ ao propomos, mesmo que brevemente, a análise da relação conflituosa entre governo e Igreja Evangélico-Luterana, por meio de seus órgãos representativos, aponta salutares elementos que corroboram com essa perspectiva. Assim como para um novo dimensionamento das pesquisas, discursos e questionamentos relacionados com o Estado Novo e seus efeitos nas comunidades étnicas classificadas como minorias.

\section{Referências}

ABREU, Luciano Aronne de. O Rio Grande Estadonovista: Interventores e Interventorias. São Leopoldo, 2005. Tese [Doutorado]. Universidade do Vale do Rio dos Sinos UNISINOS, Programa de Pós-Graduação em História, 2005.

ARENDT, Isabel Cristina. Educação, Religião e Identidade Étnica: o Allgemeine Lehrerzeintung e a escola evangélica alemã no Rio Grande do Sul. São Leopoldo: Oikos, 2008.

GERTZ, René E. O perigo alemão. Porto Alegre: Ed. da Universidade/ UFRGS, 1991.

O Estado Novo no Rio Grande do Sul. Passo Fundo: ed. Universidade de Passo Fundo, 2005.

GINZBURG, Carlo; CASTELNUOVO, Enrico; PONI, Carlo. A Micro-História e Outros Ensaios. Lisboa: Difel, 1991. (Memória e sociedade).

MARTINS, Maria Cristina Bohn; MOREIRA, Paulo Roberto Staudt (orgs.). Uma história em escalas. A microanálise e a historiografia latinoamericana. São Leopoldo: Oikos; Editora Unisinos, 2012.

NEUMANN, Rosane Marcia. "Quem nasce no Brasil é brasileiro ou traidor". As colônias germânicas e a campanha de Nacionalização. São Leopoldo, 2003. Dissertação [Mestrado]. Programa de PósGraduação em História, UNISINOS, 2003.

PETRY, Andrea Helena. É o Brasil gigante, liberto do estrangeiro, uno, coeso e forte, é o Brasil do
Brasileiro: Campanha de Nacionalização efetivada no Estado Novo. São Leopoldo, 2003. Dissertação [Mestrado]. Universidade do Vale do Rio dos Sinos - UNISINOS, Programa de PósGraduação em História, 2003.

PY, Aurélio da Silva. O Nazismo no Rio Grande do Sul (Documento secreto n.59). Porto Alegre, 1940, v.1.

A 5 coluna no Brasil: A conspiração nazi no Rio Grande do Sul. 1. ed. Porto Alegre: Globo, 1942.

RAHMAIER, Andre Helena Petry. As relações diplomáticas entre Alemanha e Brasil,

no período de 1937 a 1942. História Unisinos. 17(2):168-178, Maio/Agosto 2013

RÉMOND, René (org.). Por uma história política. Rio de Janeiro: UFRJ, FGV, 1996

SANTOS, Rodrigo Luis dos. Nomes, laços e interesses: Formação de redes sociais e estratégias políticas de católicos e evangélicoluteranos em Novo Hamburgo/RS (1924-1945). 2016. Dissertação (Mestrado em História) -Programa de Pós-Graduação em História, Universidade do Vale do Rio dos Sinos UNISINOS, São Leopoldo, RS, 2016.

As escolas confessionais como instrumento de ação política de grupos de alemães e descendentes no contexto do Estado Novo (o caso das escolas Santa Catarina e Fundação Evangélica de Novo Hamburgo - RS). 97 p. Trabalho de Conclusão de Curso [Graduação em História] - Universidade do Vale do Rio dos Sinos - UNISINOS, 2013.

TONINI, Veridiana Maria. Uma relação de amor e ódio: o caso Wolfran Metzler (Integralismo, PRP e Igreja Católica, 1932-1957). Dissertação (mestrado em História). Instituto de Filosofia e Ciências Humanas, Universidade de Passo Fundo - UPF, Passo Fundo, RS, 2003. 